\title{
COMPARATIVE STUDY BETWEEN LAPAROSCOPIC VERSUS OPEN RIGHT HEMICOLECTOMY
}

\author{
By
Abu El-Haggag Ahmed Abu El-Haggag, Mohamed Ibraheem El-Anany and Mahmoud Abd El-Hady Abd El-Aziz \\ Department of General Surgery, Faculty of Medicine, Al-Azhar University \\ Corresponding author: Abu El-Haggag Ahmed Abu El-Haggag, \\ Mobile: 01146292296, E-mail: abuelheggag.2030@gmail.com
}

\begin{abstract}
Background: Colorectal cancer (CRC) incidence and mortality rates vary markedly around the world. The right colon has a thin wall, a large caliber, and its contents are liquid; thus, obstruction is a late event in right colon cancer. Also, right colonic tumors grow large enough to be palpable through the abdominal wall before other symptoms appear.

Objective: To compare between laparoscopic and open complete mesocolic excision with central vascular ligation in right colon cancer as regards technical feasibility, advantages and disadvantages of both procedures.

Patients and Methods: This study was conducted on 30 patients admitted to Al-Azhar University Hospitals, and diagnosed as operable right sided colon cancer. It was prospectively conducted during the period from October 2019 to June 2020, and all the procedures were done on elective basis. Informed consents were obtained from all patients included in the study which approved by the local ethics committee of Al-Azhar University Hospitals. Patients were 7 (46.7\%) males and 8(53.3\%) females. Their ages ranged from 51 to 71 years with a mean age of $58.33 \pm 5.88$ in laparoscopic technique, and ranged from 50 to 70 years with a mean age of $59.93 \pm 5.20$ in open technique.

Results: There was no statistical significant difference between the studied groups regarding the mean age, gender distribution, DM, hypertension and the tumor location. There was a statistical significant difference between the studied groups regarding the incision length as the incision of the open technique was longer than the laparoscopic technique, regarding the operative time and intraoperative blood loss as the laparoscopic technique take more time than the open technique and the intraoperative blood loss during the laparoscopic technique was less than the open technique.

Conclusion: Complete mesocolic exicion(CME), with central vascular ligation is the novel key factor in the multimodal management of right colon cancer, determining a significant improvement in loco-regional control of tumors and improving the long-term oncological outcome, especially in intermediate stages of disease. it is a safe, valid, and feasible surgical method for right colon cancers, associated with smaller incisions, less operative blood loss, earlier recovery after operation, and shorter hospital stay compared with Open technique. The open technique is still superior in shorter operative time and more number of harvested lymph nodes.
\end{abstract}

Keywords: Colorectal cancer, complete mesocolic excision, laparoscopic right colectomy. 


\section{INTRODUCTION}

Colorectal cancer incidence and mortality rates vary markedly around the world. Globally, colorectal canceris the third most diagnosed cancer in males and the second in females (Fitzmaurice et al., 2017). Curative treatment for right colon cancer includes resection of the tumorbearing bowel segment. There are standard types of operations, depending on the location of the tumor. These types of resections are depended on the knowledge of lymphatic drainage and lymph node anatomy (Croner et al., 2018).

Right sided hemicolectomy is the standard type of operation for cancers in the caecum and the ascending colon (Wolff and Wang, 2012).

CME helps to keep the colonic mesentery intact, clarify the dissected area from central lymph nodes, emphasize the importance of transecting colon-feeding blood vessels at the root, and increase the range of longitudinal enterotomy. So, complete mesocolic excision provides a standardization of surgeries for colon cancer (Feng et al., 2016).

The traditional approach to right colon cancer is through open exploration but these approaches has more blood loss, prolonged postoperative hospital stay, sever postoperative pain and delayed recovery (Kahokehr et al., 2010).

Laparoscopic right colectomy for right cancer colon became a well-established procedure in the field of colorectal surgery. It has many advantages: reduction in postoperative pain, duration of regain of bowel function, and the period of hospital stay (Stormark et al., 2016).

The aim of this study was to compare between laparoscopic and open right hemicolectomy.

\section{PATIENTS AND METHODS}

This study was conducted on 30 patients admitted to AL-Azhar University Hospitals, and diagnosed as operable right sided colon cancer.

This study was prospectively conducted during the period from October 2019 to June 2020 and all the procedures were done on elective basis. Informed consents were obtained from all patients included in the study which approved by the local ethics committee of AL-Azhar University Hospitals. Patients were 7 $(46.7 \%)$ males and $8(53.3 \%)$ females in both groups. Their ages ranged from 51 to 71 years with a mean age of $58.33 \pm 5.88$ in laparoscopic technique and ranged from 50 to 70 years with a mean age of $59.93 \pm 5.20$ in open technique.

The patients were classified equally into two equal groups: Group A: Laparoscopic right hemicolectomy with complete mesocolic excision with central vascular ligation, and Group B: Open right hemicolectomy with complete mesocolic excision with central vascular ligation.

All patients were subjected to Full history taking, general examination, abdominal examination including DRE and PV, laboratory investigation (Complete blood picture, SGOT, SGPT, blood sugar, blood urea, serum creatinine, Prothrombine time, serum albumin and tumour markers), ECG, echocardiography, 
Imaging studies (chest X-ray, US abdomen, CT abdomen and pelvis) and Histopathological diagnosis (colonoscopy biopsy and tissue diagnosis).

\section{Inclusion Criteria:}

Only operable cases of right colon cancer by CT scan criteria which included no permeation of surrounding fat planes, no encasement of major vascular structures, no extensive local spread and no distant metastases or peritoneal infiltration.

\section{Exclusion Criteria:}

All cases with perforation or obstruction, metastatic colon cancer, patients undergoing colectomy including another part of the colon than right colon.

\section{Preoperative preparation:}

All patients were prepared preoperatively in the usual manner: a standard mechanical cathartic bowel preparation on the day prior to surgery. In addition, both oral and parenteral broad spectrum prophylactic antibiotics were administered.

\section{Anesthesia:}

All patients received general anesthesia. Nasogastric tube and Foley's catheter were inserted together with elastic stockings for prophylaxis against lower limb DVT.

Operative technique in patients of group A: A high-definition laparoscope was used, and the patient was at a modified lithotomy position and 15 degree tilt of the operating table to the left. After achieving pneumoperitonium $(12 \mathrm{~mm}$ $\mathrm{Hg}$ ), a 12-mm trocar was placed through an incision just above the umbilicus, and a 30-degree camera was inserted through the 12-mm trocar. The second 10-mm trocar was introduced at the upper left quadrant of the abdomen as the first major acting port. The third 5-mm trocar was introduced at the lower left quadrant as the second major active port. The fourth and the fifth 5-mm trocars were introduced at the upper right and lower right quadrants (Fig. 1). A medial to lateral dissection was done in most cases, but when the origin of ileocolic pedicles was not clearly identified, the dissection was alternated with lateral to medial fashion. The procedures of medial to lateral dissection were done as follow: Exploration of the abdomen to exclude metastasis and exposure of the superior mesenteric axis (Fig. 2). The ileocolic vessels are stretched by pulling the ceacum laterally and downward (Fig. 3). Peritoneal incision is commenced at the base of the created peritoneal fold, dissection of the anterior peritoneal fold is performed until the origin of the ileocolic vessels from the superior mesenteric vessels (by sharp dissection using harmonic scalpel) (Fig. 4\&5). Transection of the ileocolic vessels and the inconstant right colic vessels at their root with en block lymphadenectomy of the anterior aspect of superior mesenteric vessels (Fig. 6\&7). For cecal and proximal ascending colon cancers, right hemicolectomy was performed and the right branches of the middle colic artery and vein were ligated. For hepatic flexure and proximal transverse colon cancers, extended right hemicolectomy was performed and the roots of the middle colic vessels were ligated. The anatomo-embryological plane along the Tolds fascia is sharply divided (from medial to lateral and from bottom to top) respecting the integrity of the right 
mesocolon and of the retroperitoneal structures such as right ureter and gonadal vessels, dissection stop at the right lateral peritoneal fold (Fig. 8). Omentectomy was done just below the gastroepiploic vessels (Fig. 9\&10). The hepatic flexure is mobilized by dissection of the lateral hepatocolic peritoneal fold. The right lateral peritoneal fold and the ileocaecal peritoneal fold (cecal ligament) are transcected to obtain complete mobilization of the spicemen (Fig. 11). Dissection of the mesentery of the terminal ileum at $10-15 \mathrm{~cm}$ from the ileocaecal valve (Fig. 12). Then the mobilized colon was exteriorized through transverse wound in right lower abdomen (Fig. 13), and transected with adequate resection margin, then either extracorporeal stapled or hand-sewn end to end anastomosis was fashioned and 2 tube drains were placed in subhepatic and right paracolic sulci, or an intracorporeal anastomosis was performed (eliminating problems with extracorporeal delivery and unnecessary traction on the mesentery). The terminal ileum and transverse colon were aligned in side to side isoperistaltic fashion and enterostomies were made for insertion of an endostapler which was fired through these enterostomies creating the croach of the final anastomosis. The resulting common enterostomy was closed with another load of endostapler completing the side to side anastomosis.

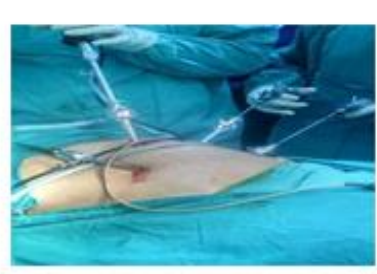

Fig. (1): Port placement for laparoscopic RT hemicolectomy.

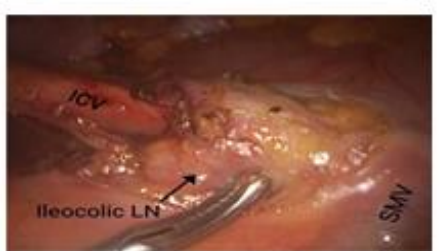

Fig. (4): Identification of superior mesenteric vessels (SMV/SMA) and ileocolic vessels (ICV/ICA), lymph nodes dissection at the root of these vessels.

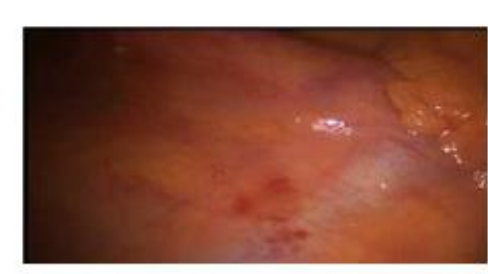

Fig. (2): Exposure of the superior mesenteric axis.

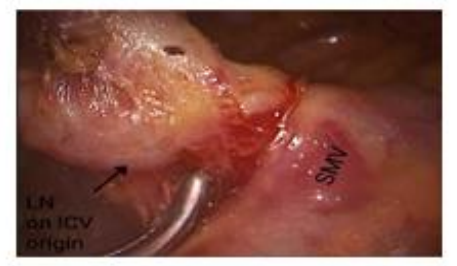

Fig. (5): Dissection start from the origin of the ileocolic vessels from superior mesenteric vessels.

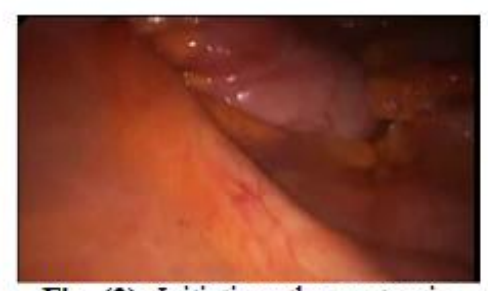

Fig. (3): Initiation: the anatomic projection of ileocolic vessels (ICA and ICV).

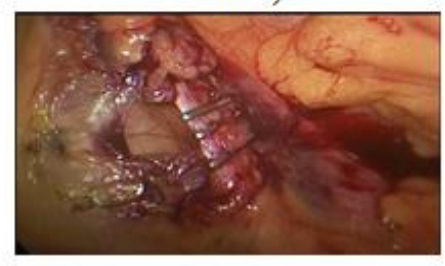

Fig. (6): Clipping of the ileocolic vessel. 


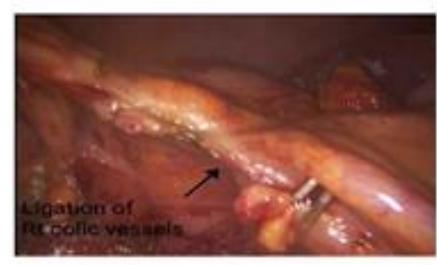

Fig. (7): Extension of transection of right branch of middle colic artery.

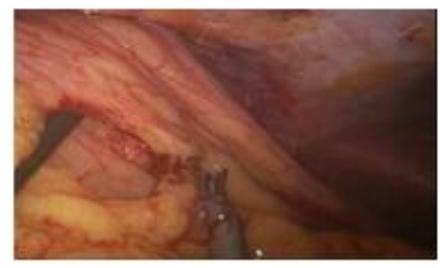

Fig. (10): Separation of gastrocolic ligament.

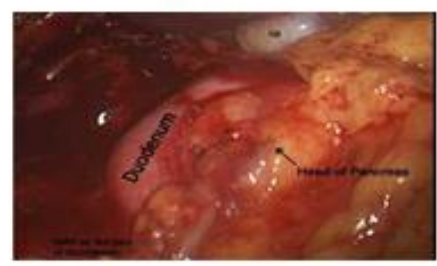

Fig. (13): The surgical field after complete procedure.

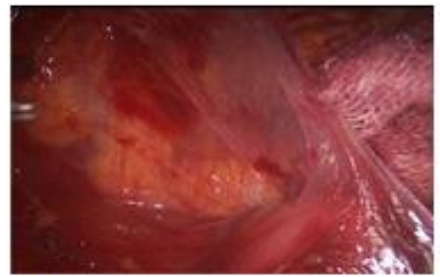

Fig. (8): Dissection is continued in the plane between Tolds fascia and the back of colonic mesentery

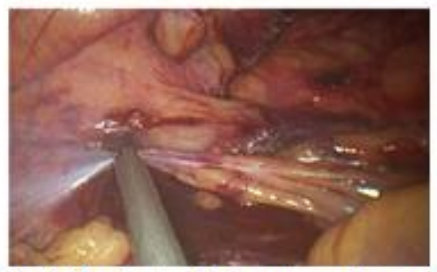

Fig. (11): Extend the extraperitoneal space (EPS) to mobilize the rigthemicolon.

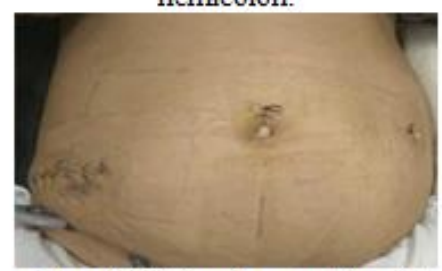

Fig. (14): Site of extraction of specimen from transverse wound in right lower abdomen (after laparoscopic right hemicolectomy)

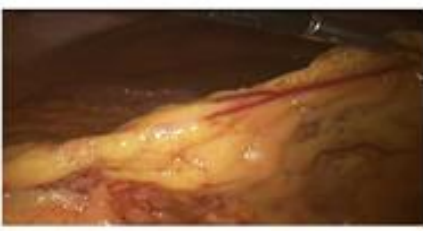

Fig. (9): Separation of gastrocolic ligament

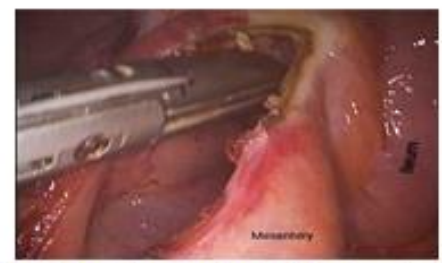

Fig. (12): Separation of the terminal ileum mesentery.

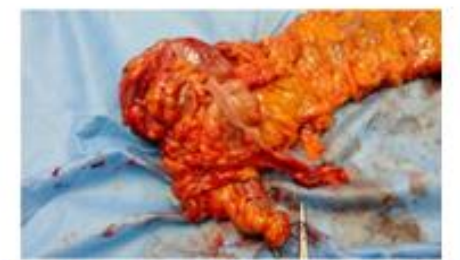

Fig. (15): Specimen include terminal ileum, caecum, ascending colon with their mesentery.
In patients of group B: The patient was placed in a supine position. A midline incision was done. Then mobilization of the colon from paracolic gutter through avascular plane of Toldt and safe guarding of the ureter, gonadals vessels and duodenum were done (Fig. 16). After that the ascending colon and hepatic flexure were released from gall bladder by dividing hepatocolic ligament and mobilized from the duodenum and Gerota's fascia. Greater omentum was separated by ligation and division just below the gasrroepiploic vessels. Identification of the ileocolic and right colic vessels was done (Fig. 17\&18). Ligation of Ileocolic and right colic vessels from their origin in case of right hemicolectomy, or ligation of ileocolic, right colic and middle colic vessels in extended right hemicolectomy to clear nodes was performed. Peritoneal incision on the mesentery of the terminal $15 \mathrm{~cm}$ ileum was completed and that part of the ileum was also mobilized. Occlusion clamps were placed at the line of resection. Another occlusion clamp was placed on the right $1 / 3^{\text {rd }}$ to $1 / 2$ of the transverse colon. Once right colon unit was completely mobilized, the division of the terminal ileum and transverse colon between clamps was done. After that constructing a safe (air tight, water tight) ileocolic end to end hand sewen anastomosis was performed. Then closure of the mesenteric defect, insertion of tube drain and closure of the abdomen were done. 


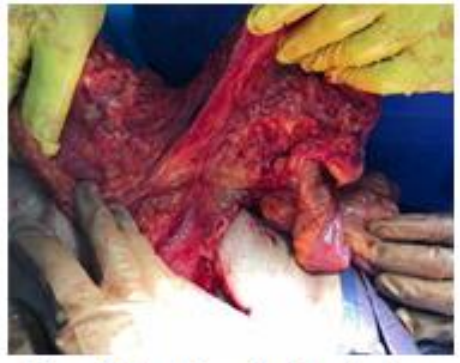

Fig. (16): After kocharization of the caecum and ascending colon

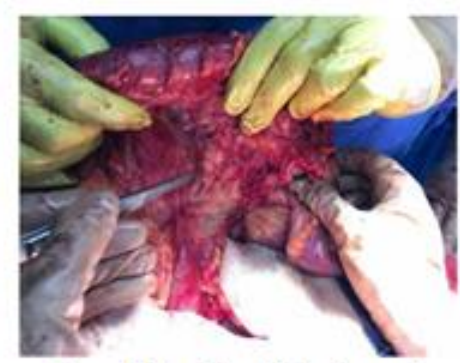

Fig. (17): Identification of ileocolic pedicle.

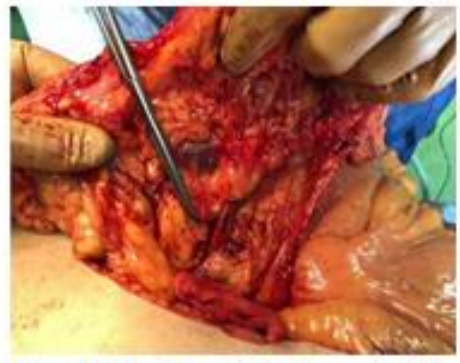

Fig. (18): Identification of right branch of middle colic vessel
Intraoperative, all patients were assessed for time of the procedure, amount of blood loss and any complications as nerve, vessel or ureteric injury.

Postoperative care: Patient was given medical treatment in the form of metronidazole and injectable antibiotics as 3rd generation cephalosporin postoperatively for five days. Ryle's tube was removed when bowel sounds were present, usually on postoperative second day. On the third postoperative day, clear liquid diet was started. Diet was advanced as tolerated. The patient was discharged from the hospital when bowel function return to normal, could tolerate a regular diet, and had adequate pain control with oral analgesics.

Follow up: Patients were followed up by the standardized follow up protocol.

They were examined by the outpatient setting after 2 weeks (postoperative) for wound infection, leakage, pathological outcome (The tumor node metastasis TNM stage, histologic grade of differentiation, number of harvested lymph nodes, lymphovascular invasion, estimation of resection margins). Every 3 months for 1 year by history taking, physical examination, carcinoembryonic antigen measurement. Every 6 months in the second year by chest, abdomen-pelvic computed tomography for detection of local or systemic recurrence.

\section{Statistical Analysis:}

Data were collected and entered to the computer using SPSS (Statistical Package for the Social Sciences) program for statistical analysis, (version 20; Inc., Chicago. IL).

Two types of statistics were done: Quantitative data were shown as mean, $\mathrm{SD}$, median, and range and qualitative data was expressed as frequency and percent. Fisher exact test was used when more than $25 \%$ of the cells have expected count less than 5. T- Test was used to compare 2 sets of quantitative. MannWhitney test was used to compare qualitative variables when the data where not normally distributed. P-value was considered statistically significant when it was less than 0.05 . 


\section{RESULTS}

There was no statistical significant difference between the studied groups regarding the mean age and gender distribution ( $\mathrm{p}$ value $>0.05$ ). Patients were $7(46.7 \%)$ males and $8(53.3 \%)$ females in both groups. Their ages ranged from 51 to 71 years with a mean age of $58.33 \pm 5.88$ in laparoscopic technique and ranged from 50 to 70 years with a mean age of $59.93 \pm 5.20$ in open technique (Table 1).

Table (1): Socio demographic data of the studied groups

\begin{tabular}{|c|c|c|c|}
\hline Studied & $\begin{array}{c}\text { Laparoscopic right } \\
\text { hemicolectomy } \\
\text { with CME } \\
\mathrm{N}=15 \\
\end{array}$ & $\begin{array}{c}\text { Open right } \\
\text { hemicolectomy } \\
\text { with CME } \\
\mathrm{N}=15 \\
\end{array}$ & P-VALUE \\
\hline $\begin{array}{c}\text { Age : } \\
\text { Mean } \pm \text { SD } \\
\text { Median } \\
\text { Range } \\
\end{array}$ & $\begin{array}{c}58.33 \pm 5.88 \\
58.00 \\
51-71 \\
\end{array}$ & $\begin{array}{c}59.93 \pm 5.20 \\
60.00 \\
50-70 \\
\end{array}$ & $>0.05$ \\
\hline & No $\quad(\%)$ & No $\quad(\%)$ & $\mathrm{p}$-value \\
\hline $\begin{array}{c}\text { Gender } \\
\text { Males } \\
\text { Females }\end{array}$ & $\begin{array}{l}46.7 \% \\
53.3 \%\end{array}$ & $\begin{array}{l}46.7 \% \\
53.3 \%\end{array}$ & $>0.05$ \\
\hline
\end{tabular}

There was no statistical significant difference between the studied groups regarding DM and hypertension. In laparoscopic complete mesocolic excision, complete mesocolic excision group about
4 patients were diabetic and 3 patients were hypertensive and in open complete mesocolic excision group about 4 patients were diabetic and only 2 patients were hypertensive (Table 2).

Table (2): History of comorbidities among the studied groups

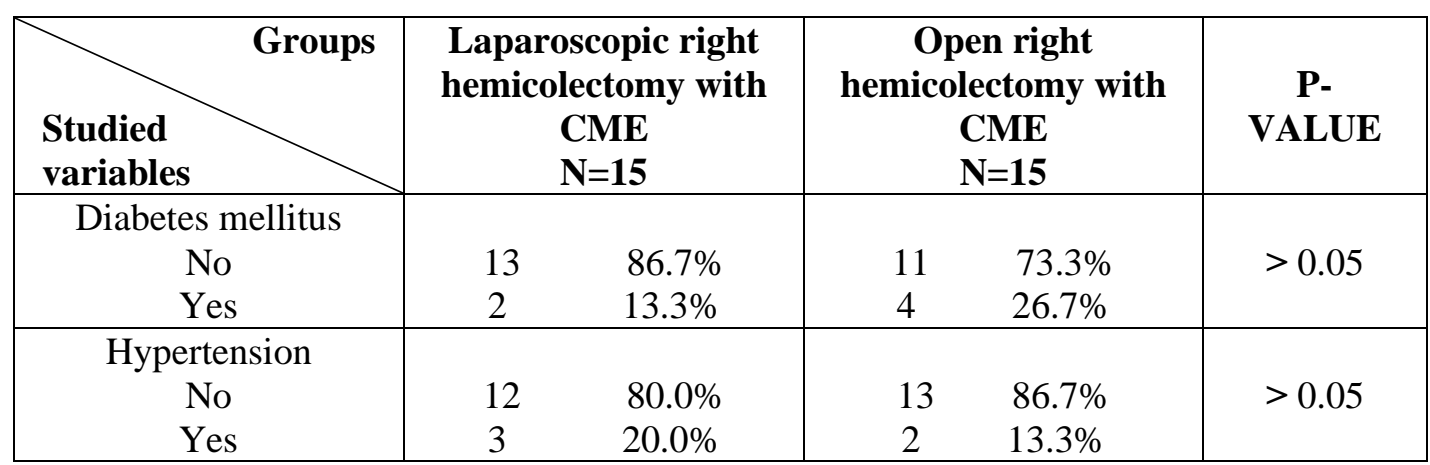

There was no statistical significant difference between the studied groups regarding the tumor location (Table 3). 
Table (3): Tumor location among the studied groups

\begin{tabular}{|c|rc|cc|c|}
\hline Groups & $\begin{array}{c}\text { Laparoscopic right } \\
\text { hemicolectomy } \\
\text { with CME } \\
\text { variables }\end{array}$ & $\begin{array}{c}\text { Open right } \\
\text { hemicolectomy } \\
\text { with CME } \\
\text { N=15 }\end{array}$ & P-VALUE \\
\hline Ascending colon & 7 & $46.7 \%$ & 8 & $58.3 \%$ & $>0.05$ \\
Cecum & 5 & $33.3 \%$ & 4 & $26.7 \%$ & \\
Hepatic flexure & 3 & $20.0 \%$ & 3 & $20.0 \%$ & \\
\hline
\end{tabular}

There was a statistical high significant difference between the studied groups regarding the incision length as the incision of the open technique is longer than the laparoscopic technique ( $\mathrm{p}$ value $<$ 0.001). It also showed that, there was a statistical high significant difference between the studied groups regarding the operative time and intraoperative blood loss as the laparoscopic technique take more time than the open technique and the intraoperative blood loss during the laparoscopic technique is less than the open technique ( $\mathrm{p}$ value $<0.001)$ / (Table 4).

Table (4): Intra Operative parameters between the studied groups

\begin{tabular}{|c|c|c|c|}
\hline Groups & $\begin{array}{c}\text { Laparoscopic right } \\
\text { hemicolectomy } \\
\text { with CME } \\
\mathbf{N}=15 \\
\end{array}$ & $\begin{array}{c}\text { Open right } \\
\text { hemicolectomy } \\
\text { with CME } \\
\mathrm{N}=15 \\
\end{array}$ & P-VALUE \\
\hline $\begin{array}{c}\text { Incision length }(\mathrm{cm}) \\
\text { Mean } \pm S D \\
\text { Median } \\
\text { Range } \\
\end{array}$ & $\begin{array}{c}6.02 \pm 0.44 \\
6.0000 \\
5.20-6.80 \\
\end{array}$ & $\begin{array}{c}17.5 \pm 0.25 \\
18.5 \\
152.20 \\
\end{array}$ & $<0.001$ \\
\hline $\begin{array}{c}\text { Operative time (Min) } \\
\text { Mean } \pm \text { SD } \\
\text { Median } \\
\text { Range }\end{array}$ & $\begin{array}{c}180.0 \pm 20.0 \\
179.00 \\
140-205\end{array}$ & $\begin{array}{c}157.34 \pm 15.0 \\
155.00 \\
90-175\end{array}$ & $<0.002$ \\
\hline $\begin{array}{l}\text { Blood loss }(\mathrm{ml}) \\
\text { Mean } \pm \text { SD } \\
\text { Median } \\
\text { Range }\end{array}$ & $\begin{array}{c}92.00 \pm 24.986 \\
85.00 \\
65-190\end{array}$ & $\begin{array}{c}200.6 \pm 50.5 \\
220.00 \\
127-360\end{array}$ & $<0.001$ \\
\hline
\end{tabular}

There was a statistical high significant difference between the studied groups regarding the hospital stay. The hospital stay in laparoscopic CME group is shorter than the open group (3- 6 days vs. 5-7 days, $\mathrm{p}$ value $<0.001)$ / (Table 5).

Table (5): Hospital stay duration among the studied groups

\begin{tabular}{|c|c|c|c|}
\hline Groups & $\begin{array}{c}\text { Laparoscopic right } \\
\text { hemicolectomy with } \\
\text { CME } \\
\text { N=15 }\end{array}$ & $\begin{array}{c}\text { Open right } \\
\text { hemicolectomy } \\
\text { with CME } \\
\text { N=15 }\end{array}$ & $\begin{array}{c}\text { P- } \\
\text { VALUE }\end{array}$ \\
\hline $\begin{array}{c}\text { Hospital stay Duration (Day) } \\
\text { Mean } \pm \text { SD } \\
\text { Median } \\
\text { Range }\end{array}$ & $4.40 \pm 0.91$ & $5.73 \pm 0.799$ & $<0.001$ \\
& 4.00 & 6.00 & \\
& $3-6$ & $5-7$ & \\
\hline
\end{tabular}


There was no statistical significant difference between the studied groups regarding the tumour size, the number of retrieved LNs, TNM classification and the histopathology findings ( $\mathrm{p}$ value $>0.05)$ / (Table 6).

Table (6): Histopathological study among the studied group

\begin{tabular}{|c|c|c|c|}
\hline Groups & $\begin{array}{c}\text { Laparoscopic right } \\
\text { hemicolectomy with } \\
\text { CME } \\
\text { N=15 }\end{array}$ & $\begin{array}{c}\text { Open right } \\
\text { hemicolectomy } \\
\text { with CME } \\
\mathbf{N}=15\end{array}$ & P-VALUE \\
\hline $\begin{array}{c}\text { Tumor size } \\
\text { Mean } \pm \text { SD } \\
\text { Median } \\
\text { Range }\end{array}$ & $\begin{array}{c}4.31 \pm 3.50 \\
4.5 \\
1-11\end{array}$ & $\begin{array}{c}5.25 \pm 4.34 \\
5 \\
1-18\end{array}$ & $>0.05$ \\
\hline $\begin{array}{c}\text { No.of retrieved l.Ns } \\
\text { Mean } \pm \text { SD } \\
\text { Median } \\
\text { Range }\end{array}$ & $\begin{array}{c}27.0 \pm 8.23 \\
26 \\
18-36\end{array}$ & $\begin{array}{c}32.0 \pm 10.38 \\
29 \\
20-49\end{array}$ & $>0.05$ \\
\hline & No $\quad(\%)$ & No $\quad(\%)$ & $p$-value \\
\hline $\begin{array}{c}\text { TNM Classification } \\
\text { I } \\
\text { II } \\
\text { III }\end{array}$ & $\begin{array}{l}13.3 \% \\
40.0 \% \\
46.7 \%\end{array}$ & $\begin{array}{cc}4 & 13.3 \% \\
14 & 46.7 \% \\
12 & 40.0 \%\end{array}$ & $>0.05$ \\
\hline $\begin{array}{c}\text { Histopathology: } \\
\text { Well Differentiated } \\
\text { Moderately } \\
\text { Differentiated } \\
\text { Poor Differentiated } \\
\text { Mucinous }\end{array}$ & $\begin{array}{rl}6 & 20 \% \\
16 & 53.3 \% \\
6 & 20 \% \\
& \\
2 & 6.7 \%\end{array}$ & $\begin{array}{lr}8 & 26.7 \% \\
14 & 46.7 \% \\
8 & 26.7 \% \\
& \\
0 & 0 \%\end{array}$ & $>0.05$ \\
\hline
\end{tabular}

There was no statistical significant difference between the studied groups regarding postoperative complications as ileus, anastomotic leak, postoperative bleeding, wound infection, intra- abdominal sepsis and incisional hernia ( $\mathrm{p}$ value $<0.05$ ). The regain of bowel motion was so close in both groups (2-4 days vs. $1-5$ days, $p$ value $=0.42) /($ Table 7$)$. 
Table (7): Postoperative parameters between the studied groups

\begin{tabular}{|c|c|c|c|}
\hline Groups & $\begin{array}{c}\text { Laparoscopic right } \\
\text { hemicolectomy with } \\
\text { CME } \\
\text { N=15 }\end{array}$ & $\begin{array}{c}\text { Open right } \\
\text { hemicolectomy } \\
\text { with CME } \\
\text { N=15 }\end{array}$ & P-VALUE \\
\hline $\begin{array}{c}\text { Regain of bowel Motion (day) } \\
\text { Mean } \pm \text { SD } \\
\text { Median } \\
\text { Range }\end{array}$ & $\begin{array}{c}2.9 \pm 0.78 \\
3 \\
2-4\end{array}$ & $\begin{array}{c}3.1 \pm 0.56 \\
4 \\
1-5\end{array}$ & $>0.05$ \\
\hline $\begin{array}{c}\text { Post-operative complications: } \\
\text { No } \\
\text { Yes }\end{array}$ & $\begin{array}{l}70.0 \% \\
30.0 \%\end{array}$ & $\begin{array}{cc}22 & 73.3 \% \\
8 & 26.7 \%\end{array}$ & $>0.05$ \\
\hline $\begin{array}{l}\text { Ilies } \\
\text { No } \\
\text { Yes }\end{array}$ & $\begin{array}{l}93.3 \% \\
6.7 \%\end{array}$ & $\begin{array}{ll}27 & 90 \% \\
3 & 10 \%\end{array}$ & $>0.05$ \\
\hline $\begin{array}{c}\text { Anastomotic leak } \\
\text { No } \\
\text { Yes }\end{array}$ & $\begin{array}{l}96.7 \% \\
3.3 \%\end{array}$ & $\begin{array}{rl}30 & 100.0 \% \\
0 & 0.0 \%\end{array}$ & $>0.05$ \\
\hline $\begin{array}{c}\text { Anastomotic bleeding } \\
\text { No } \\
\text { Yes } \\
\end{array}$ & $\begin{array}{ll}27 & 90.0 \% \\
3 & 10.0 \% \\
\end{array}$ & $\begin{array}{rc}30 & 100.0 \% \\
0 & 0.0 \% \\
\end{array}$ & $>0.05$ \\
\hline $\begin{array}{c}\text { Wound infection } \\
\text { No } \\
\text { Yes }\end{array}$ & $\begin{array}{rl}29 & 96.7 \% \\
1 & 3.3 \%\end{array}$ & $\begin{array}{cc}27 & 90.0 \% \\
3 & 10.0 \% \\
\end{array}$ & $>0.05$ \\
\hline $\begin{array}{c}\text { Intraabdominal sepsis } \\
\text { No } \\
\text { Yes }\end{array}$ & $\begin{array}{l}93.3 \% \\
6.7 \%\end{array}$ & $\begin{array}{rl}29 & 96.7 \% \\
1 & 3.3 \%\end{array}$ & $>0.05$ \\
\hline $\begin{array}{c}\text { Incisional hernia } \\
\text { No } \\
\text { Yes }\end{array}$ & $\begin{array}{c}100.0 \% \\
0.0 \%\end{array}$ & $\begin{array}{rl}29 & 93.3 \% \\
1 & 6.7 \%\end{array}$ & $>0.05$ \\
\hline
\end{tabular}

This table showed that, there was no statistical significant difference between the studied groups regarding follow up duration between the studied groups $(\mathrm{p}$ value $>0.05$ ). During the follow-up of the patients, there was one case of tumor local recurrence in laparoscopic group, no metastasis, nor were cancer-related deaths observed in either group (Table 8).

Table (8): Follow up and local recurrence between the studied groups

\begin{tabular}{|c|c|c|c|}
\hline Studied & $\begin{array}{c}\text { Laparoscopic right } \\
\text { hemicolectomy } \\
\text { with CME } \\
\mathrm{N}=15\end{array}$ & $\begin{array}{c}\text { Open right } \\
\text { hemicolectomy } \\
\text { with CME } \\
\text { N=15 }\end{array}$ & P-VALUE \\
\hline $\begin{array}{c}\text { Follow up duration (month) } \\
\text { Mean } \pm \text { SD } \\
\text { Median } \\
\text { Range }\end{array}$ & $\begin{array}{c}24-33 \pm 4.79 \\
24.00 \\
11-36\end{array}$ & $\begin{array}{c}26-53 \pm 5.399 \\
26.00 \\
12-35\end{array}$ & $>0.05$ \\
\hline & No $\quad(\%)$ & No $\quad(\%)$ & p-value \\
\hline $\begin{array}{c}\text { Local recurrence } \\
\text { Yes } \\
\text { No }\end{array}$ & $\begin{array}{l}3.3 \% \\
96.7 \%\end{array}$ & $\begin{array}{rc}0 & 0.0 \% \\
30 & 100.0 \% \\
\end{array}$ & $>0.05$ \\
\hline
\end{tabular}




\section{DISCUSSION}

Complete excision of the primitive dorsal mesenterium along the anatomoembryological surgical planes by means of complete mesocolic excision is now the standard of care for colonic cancers. Technical strategies for complete mesocolic exicion include two aspects: sharp separation of visceral and parietal fascia, based on embryonic anatomy, to minimize the likelihood of an incomplete resection, and ligation at the root of central supply vessels and more radical lymph node dissection for improving oncological outcomes (Adamina et al., 2012).

However, the right hemicolectomy is performed routinely worldwide, the feasibility and safety of complete mesocolic excision has been shown in open and laparoscopic surgeries (Bae et al., 2014).

In the present study, we compared between laparoscopic and open complete mesocolic excision with central vascular ligation in right colon cancer as regards technical feasibility, positive and negative impacts of both techniques. The statistical analysis revealed no significant difference between the studied groups as regards age and sex distribution, this ensures that the demographic data has no effect on the results of the study indicating no bias in it. Regarding the comorbidities of the patients, analysis of the results showed that, there was no statistical significant difference between the studied groups regarding DM and hypertension. In laparoscopic CME group about 4 patients were diabetic and 6 patients were hypertensive and in open CME group about 8 patients were diabetic and only 4 patients were hypertensive.

These results were in agreement with those reported by Sheng et al. (2017) who stated that the open and laparoscopic techniques were the same in age, sex distribution, tumor localization, and potential comorbidities. Observed that there was a statistical significant difference with a higher prevalence of open procedure between the patients aged 60 or over.

In this study, there was a statistical high significant difference between the studied groups regarding the incision length as the incision of the open technique was longer than the laparoscopic technique.

This result agreed with the study done by Negoi et al. (2017) who reported that, patients from the laparoscopic group had a shorter incision, Also; Huang et al. (2015) reported that the laparoscopic $\mathrm{CME}$ group had a significantly shorter total incision length than the open CME group.

The duration of surgery remained one of the largest obstacles for laparoscopic CME. In our study, there was a statistical high significant difference between the laparoscopic and open procedures regarding the operative time as the laparoscopic technique take more time (range $=140-205 \mathrm{~min})$ than the open technique.

This result was in agreement with $\mathrm{Li}$ et al. (2018) who demonstrated that the operation time in the laparoscopic CME group was statistically longer than that in the open CME group another study by Zhao et al. (2014) reported that the mean operative time was significantly longer in 
the laparoscopic CME group than that in the open CME group.

On the other hand, Stergios et al. (2017) reported that there was a statistically significant decrease of the operative time for the laparoscopic group compared to the open group as their surgical team had more skills and experience in laparoscopic technique.

Regarding intraoperative blood loss and the hospital stay, there was a statistical high significant difference between the studied groups as the intraoperative blood loss during the laparoscopic technique was less than the open technique detected in suction device container and soaked guaze, and hospital stay in laparoscopic group was shorter than the open group.

These results were in agreement with Bae et al. (2014) who reported that there was significant differences between open and laparoscopic groups in blood loss and hospital stay duration days, preferred the laparoscopic CME group. Also, Sheng et al. (2017) reported that patients in laparoscopic CME group had less operative blood loss and shorter hospital stay than those of the patients in the Open CME group.

In this study, there was no statistical significant difference between the laparoscopic and open groups regarding the tumour size, TNM classification and the histopathology findings. The number of harvested LNs in laparoscopic CME and open CME groups were.

These results were so close to the study done by Huang et al. (2015) who reported that there was no significant difference in TNM classification between the open and laparoscopic techniques. The lengths of resected specimens in the laparoscopic and open groups were the same, as were the average number of harvested lymph nodes. Kang et al. (2014) demonstrated that the effect of the number of harvested lymph nodes after right colon cancer surgery on oncological outcomes has been emphasized.. Some studies have suggested that the number of retrieved lymph nodes and the proportion of involved to uninvolved nodes are significant prognostic factors even in the cases with stage III disease, in which improved survival is seen with increased lymph node yield.

West et al. (2010) demonstrated that complete mesocolic excision with central vascular ligation remove more tissue around a tumor with end result of a maximal lymph node harvest.

The present study showed that there was no statistical significant difference between the laparoscopic and open CME groups regarding postoperative complications. The regain of bowel motion was so close in both groups. The postoperative complication rate in the laparoscopic CME group was 30\%, and the complications included ileus, anastomotic leak that managed conservatively, postoperative bleeding that converted to open technique, intraabdominal sepsis managed by ultrasound guided drainage of localized collection and the by antibiotic according to culture and sensitivity. The complication rate in the open CME group was $26.7 \%$, including ileus, wound infection, intraabdominal sepsis managed by antibiotic according to culture and sensitivity, and incisional hernia. 
Chen et al. (2017) reported that. the patients in laparoscopic CME group had earlier regain of bowel function after the operation and comparable incidence of postoperative complications compared to the patients in the open group. Huang et al. (2015) reported that there was no statistical difference between both groups regarding the post-operative complications and their rates in laparoscopic CME and open CME groups. Also, Li et al. (2018) demonstrated that, there was no statistical difference in the postoperative complication rate between the laparoscopic complete mesocolic excision and open CME groups. The postoperative complication rate in the laparoscopic complete mesocolic excision group was $10.0 \%$, and the complications included incision infections and an intestinal obstruction. The complication rate in the open complete mesocolic excision group was $10.4 \%$, including incision infections, a pulmonary infection, and postoperative anastomotic bleeding.

Regarding the follow up duration, there was no statistical significant difference between laparoscopic complete mesocolic excision and open complete mesocolic excision groups. During the follow-up, there was one case of tumor local recurrence in laparoscopic group, no metastasis, nor were cancer-related deaths observed in either group. These results were close to the study of Sheng et al. (2017).

\section{CONCLUSION}

Laparoscopic complete mesocolic excision with central vascular ligation procedure is a safe, valid, and feasible surgical method for right colon cancers. Laparoscopic complete mesocolic excision with central vascular ligation is associated with smaller incisions, less operative blood loss, earlier recovery after operation, and shorter hospital stay compared with open technique. The open technique is still superior in shorter operative time and more number of harvested lymph nodes.

\section{REFERENCES}

1. Adamina, M., Manwaring, M. L., Park, K. J. and Delaney, C. P. (2012): Laparoscopic complete mesocolic excision for right colon cancer. Surgical Endoscopy, 26(10), 29762980.

2. Bae, S. U., Saklani, A. P., Lim, D. R., Kim, D. W., Hur, H., Min, B. S., and Kim, N. K. (2014): Laparoscopic-assisted versus open complete mesocolic excision and central vascular ligation for right-sided colon cancer. Annals of Surgical Oncology, 21(7); 22882294.

3. Chen, Z., Sheng, Q., Ying, X. and Chen, W. (2017): Comparison of laparoscopic versus open complete mesocolic excision in elderly patients with right hemicolon cancer: retrospective analysis of one single cancer. Int J Clin Exp Med; 10(3): 5116-24.

4. Croner, R. S., Ptok, H., Merkel, S. and Hohenberger, W. (2018): Implementing complete mesocolic excision for colon cancermission completed?. Innovative Surgical Sciences, 3(1):17-29.

5. Feng, B., Zhang, S., Yan, X., Ma, J., Sun, J., Lu, J.,and Lu, A. (2016): Operational approaches for laparoscopic complete mesocolic excision in right hemicolon cancer. Minimally Invasive Approach to Colorectal Diseases, 111.Ann Laparsc Endosc Surg;1:26.

6. Fitzmaurice, C., Allen, C., Barber, R. M., Barregard, L., Bhutta, Z. A., Brenner, H., and Fleming, T. (2017): Global Burden of Disease Cancer Collaboration Global, regional, and national cancer incidence, mortality, years of life lost, years lived with disability, and disability-adjusted life-years for 32 cancer groups, 1990 to 2015: a systematic analysis for 


\section{ABU EL-HAGGAG AHMED ABU EL-HAGGAG et al.,}

the Global Burden of Disease Study. JAMA Oncol; 3(4): 524-548.

7. Huang, J. L., Wei, H. B., Fang, J. F., Zheng, Z. H., Chen, T. F., Wei, B., and Liu, J. P. (2015): Comparison of laparoscopic versus open complete mesocolic excision for right colon cancer. International Journal of Surgery, 23: $12-17$.

8. Kahokehr, A., Sammour, T., ZargarShoshtari, K., Srinivasa, S.and Hill, A. G. (2010): Recovery after open and laparoscopic right hemicolectomy: a comparison. Journal of Surgical Research, 162(1): 11-16.

9. Kang, J., Kim, I. K., Kang, S. I., Sohn, S. K. and Lee, K. Y. (2014): Laparoscopic right hemicolectomy with complete mesocolic excision. Surgical Endoscopy, 28(9): 27472751.

10.Li, T., Meng, X. L.and Chen, W. (2018): Safety and Short-term Efcacy of a Laparoscopic Complete Mesocolic Excision for the Surgical Treatment of Right Hemicolon Cancer. Clinical Surgery Research Communications, 2(2): 29-33.

11. Negoi, I., Hostiuc, S., Negoi, R. I.and Beuran, M. (2017): Laparoscopic vs open complete mesocolic excision with central vascular ligation for colon cancer: A systematic review and meta-analysis. World Journal of Gastrointestinal Oncology, 9(12): 475- 419

12.Sheng, Q. S., Pan, Z., Chai, J., Cheng, X. B., Liu, F. L., Wang, J. H., and Lin, J. J. (2017): Complete mesocolic excision in right hemicolectomy: comparison between hand- assisted laparoscopic and open approaches. Annals of Surgical Treatment and Rresearch, 92(2): 90-96.

13. Stergios, K., Pergialiotis, V., Frountzas, M., Nalwaya, P., Kontzoglou, K.and Mohapatra, S. D. (2017): Laparoscopic Versus Open Colectomies: Enhanced Surgical Skills And Rigorous Patient Selection May Improve Operative Times Without Compromising Outcomes. J Surg, 4(3): 555- 636.

14. West, N. P., Hohenberger, W., Weber, K., Perrakis, A., Finan, P. J.and Quirke, P. (2010): Complete mesocolic excision with central vascular ligation produces an oncologically superior specimen compared with standard surgery for carcinoma of the colon. Journal of Clinical Oncology, 28(2): 272-278.

15. Wolff, B. G. and Larson, D. W. (2012): Right hemicolectomy for treatment of cancer: open technique. Fischer JE. Mastery of Surgery. 5th ed. pbl Lippincott, Williams \& Wilkins, p. 138.

16. Zhao, L. Y., Chi, P., Ding, W. X., Huang, S. R., Zhang, S. F., Pan, K., and Li, G. X. (2014): Laparoscopic vs open extended right hemicolectomy for colon cancer. World Journal of Gastroenterology: WJG, 20(24): $7926-7932$. 


\section{دراسة المقارنة بين استنئصال القولون الأيمن جر احيا وعن

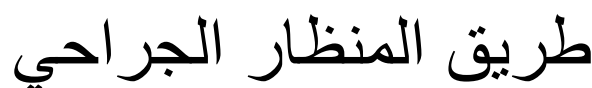

أبوالحجاج أحمد أبوالحجاج ،محمد إبراهيم العناني، محمود عبد الهادي عبد العزيز قسم الجراحة العامة، كلية الطب، جامعة الأزهر

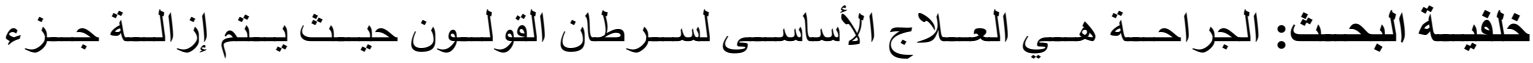

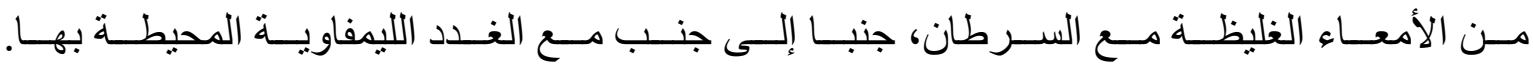

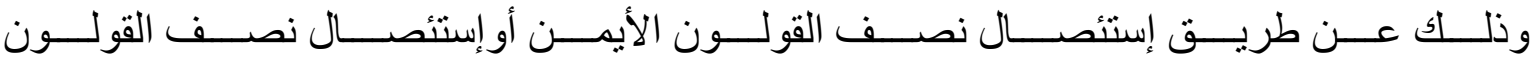

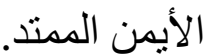

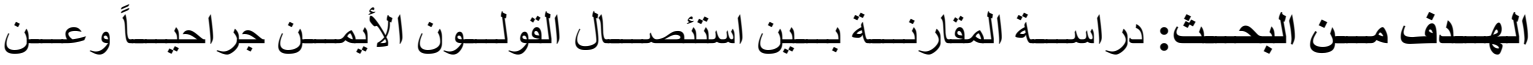

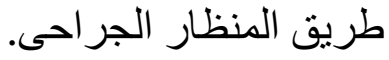

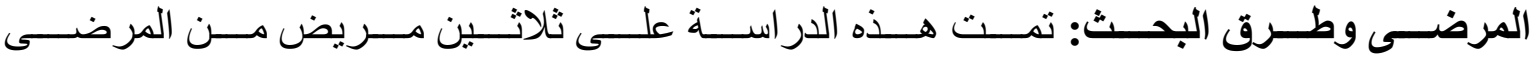

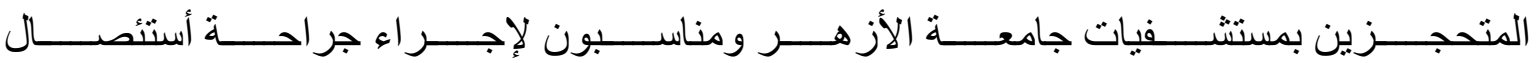

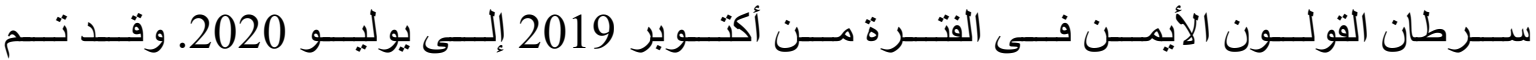

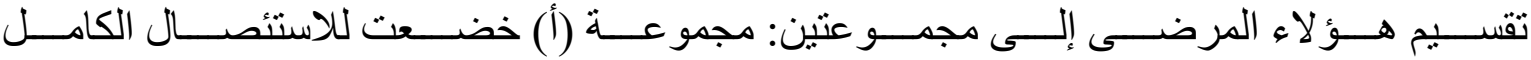

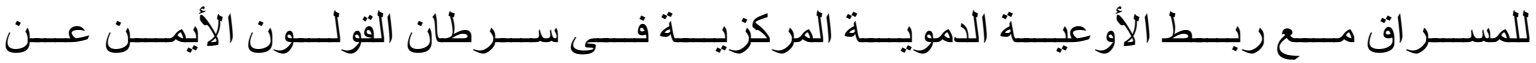

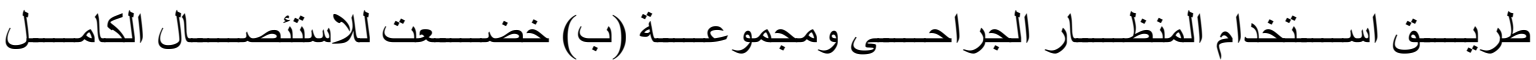

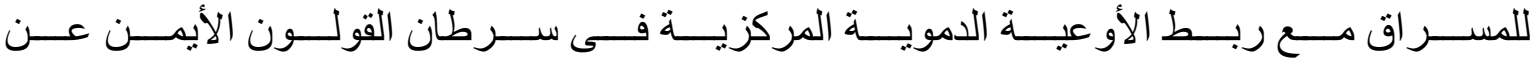

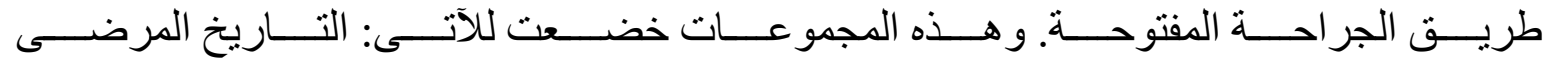

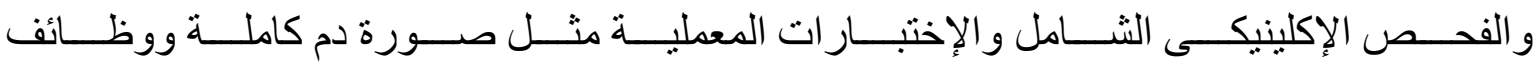

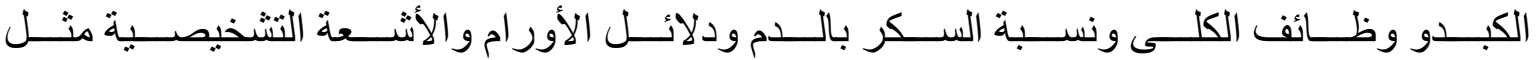

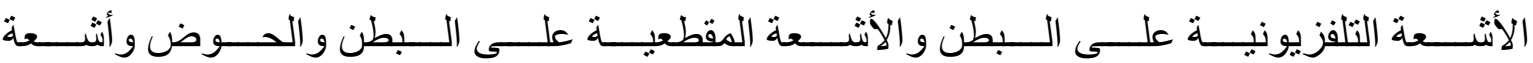
عادية على الصدرو تحليل أنسجة الورم بعد أخذ مسحة منه.

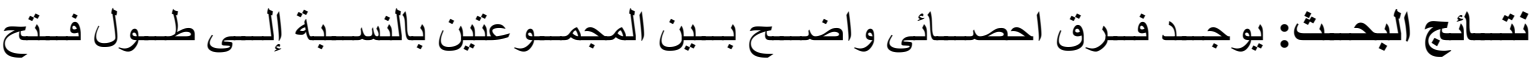

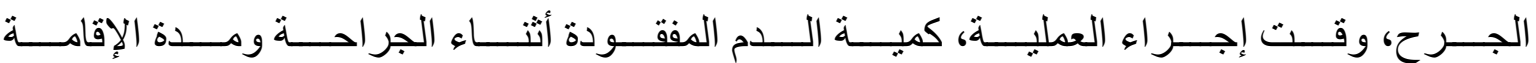

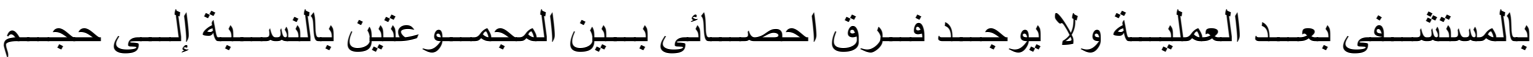

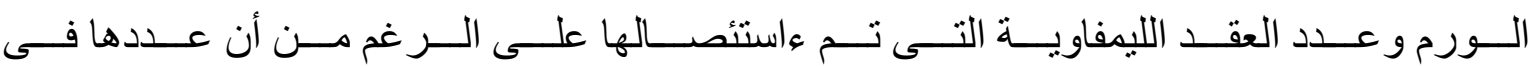




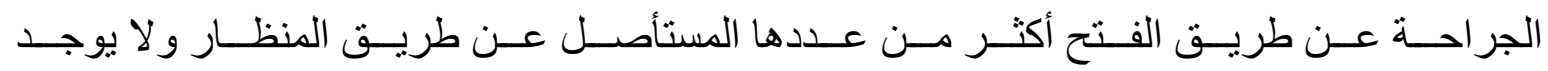

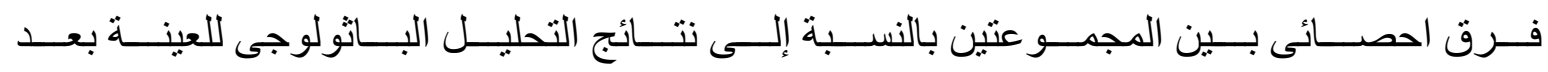

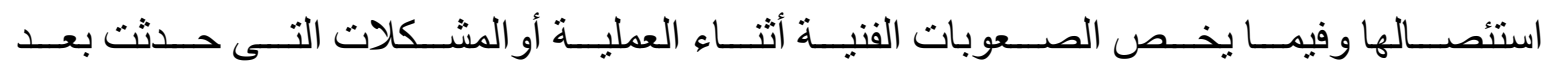

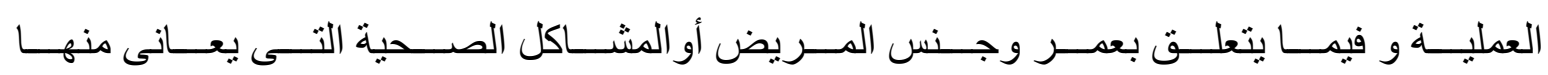
المريض.

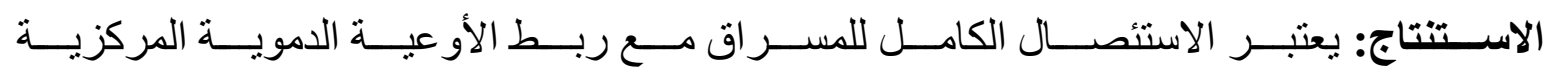

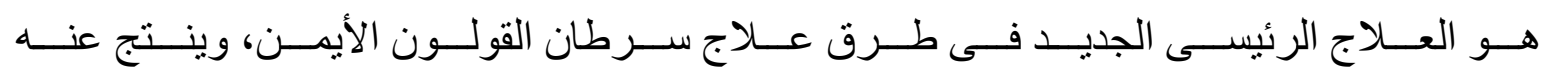

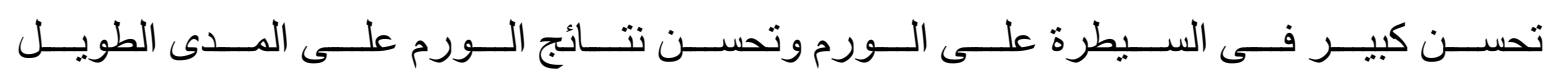

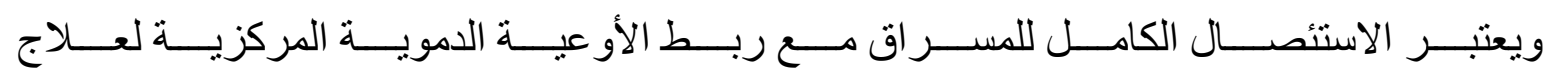

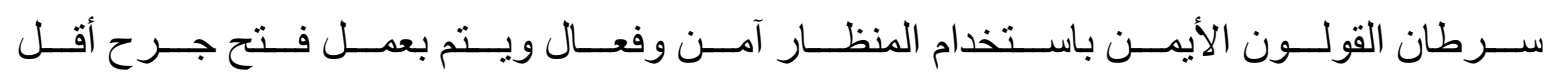

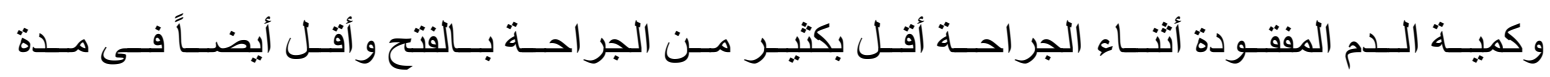

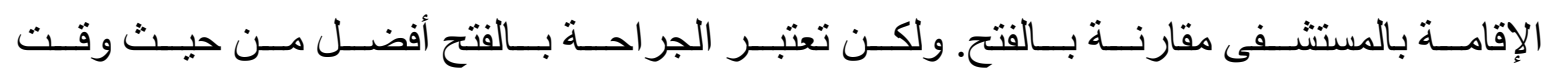

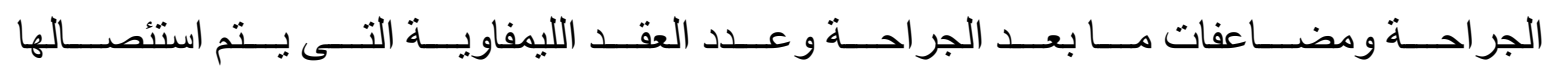

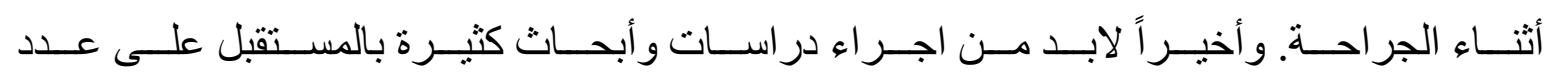

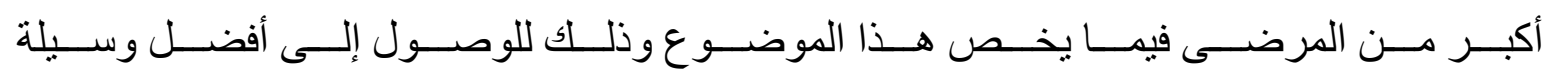
لإنهاء هذا السجال المستمر. 